\title{
Development and Research of Polyurethane Foam Composite Materials with Albucid
}

\author{
Tetiana Vislohuzova*, Rita Rozhnova, Nataliia Galatenko \\ Department of Polymers of Medical Appointment, Institute of Macromolecular Chemistry of the National Academy of Sciences of Ukraine, \\ Kyiv, Ukraine
}

Email address:

rudenchyk@gmail.com (T. Vislohuzova),rozhnovarita@gmail.com (R. Rozhnova), politoks@merlin.net.ua (N. Galatenko)

${ }^{*}$ Corresponding author

\section{To cite this article:}

Tetiana Vislohuzova, Rita Rozhnova, Nataliia Galatenko. Development and Research of Polyurethane Foam Composite Materials with Albucid. American Journal of Polymer Science and Technology. Vol. 7, No. 3, 2021, pp. 38-43. doi: 10.11648/j.ajpst.20210703.11

Received: July 12, 2021; Accepted: July 23, 2021; Published: August 4, 2021

\begin{abstract}
In modern surgery there is a need for restorative and reconstructive operations in the orbit and periorbital area as a result of eye injuries. This study is aimed at the development and research of the structure and properties of polyurethane foam (PUF) composite materials filled by antimicrobial drug substance albucid as implants for ophthalmic surgery. PUF composite materials with albucid (in the amount of $5 \mathrm{wt} . \%$ ) based on diisocyanate prepolymer (synthesized from polyoxypropylene glycol and 2.4-; 2.6-toluylene diisocyanate) were obtained. The structure, adhesive, thermophysical and thermogravimetric properties, morphology of composite materials have been characterized using Fourier transform infrared (FTIR), mechanical tests, differential scanning calorimetry (DSC), thermogravimetric analysis (TGA) and transmission optical microscopy (TOM). It is established that the immobilization of albucid occurs due to intermolecular hydrogen bonds by the method of IR spectroscopy. According to the results of physical-mechanical tests the presence of albucid in the composition of polyurethane foams does not affect the value of the adhesive strength of composite materials. According to DSC the investigated systems are single-phase with a glass transition temperature from minus 48.40 to minus $48.64^{\circ} \mathrm{C}$. The introduction of albucid into the PUF causes a decrease of the specific heat capacity at the glass-transition temperature and does not affect on the $\mathrm{T}_{\mathrm{g}}$ of composite materials. According to the results of analysis of TOM photomicrograph, it was found that the presence of albucid in the composite materials leads to a decrease in the porosity percentage, an increase in the quantity of pores with a diameter less than $300 \mu \mathrm{m}$, which is $82 \%$ (while for PUF it is $69.5 \%$ ) and the absence of pores with a diameter more than $954 \mu \mathrm{m}$. Thermogravimetric characteristics indicate the heat resistance of the synthesized PUF to a temperature of $162.84^{\circ} \mathrm{C}$, which makes it possible to carry out dry sterilization of samples without changing their characteristics. Therefore, the obtained PUF composite materials with albucid exhibit adhesion, heat resistance and have a microporous structure. It allows us to conclude that they are promising materials that can be used in medical practice, in particular in ophthalmic surgery as implants with antimicrobial action.
\end{abstract}

Keywords: Polyurethane Foam, Composite Material, Albucid, Porosity

\section{Introduction}

In modern surgery there is a need for restorative and reconstructive operations in the orbit and periorbital area as a result of eye injuries. Therefore, the search and implementation of new materials as multifunctional polymer implants for ophthalmic surgery is a very important task.

Polyurethane foam (PUF) matrix is used in the manufacture of composite materials for medical purposes as dressings materials for wound closures [1-4], adhesive compositions for use in abdominal [5] and maxillofacial surgery [6], traumatology for plasty of soft and bone tissue $[7,8]$. However, it is known to use a PUF matrix as an implant material. Thus, a medical glue which is a composite material based on cross-linked polyurethane (obtained from oligoetherurethane diisocyanate and folic acid) is intended for implantation and plastic defects, for gluing or fixation of soft tissues and bones. It is characterized by high 
biocompatibility and adhesion to tissues, hydrophilicity and ability to biodegradation. In the humid environment of the wound, the glue foams thereby forming of elastic smallporous sponge which does not deform the surrounding tissues and does not disrupt their functional activity. The medical glue forms an adhesive seam which firmly holds tissues at all stages of wound healing and stimulates regenerative processes [9].

The authors [10] have developed biocompatible PUF based on lysine diisocyanate and glycerin as implant materials with controlled long-term release of the anti-cancer drug substance 7-tert-butyldimethylsilyl-10hydroxycamptothecin, which occurs by diffusion and passive hydrolysis of urethane bonds. It was found that PUF filled with 7-tert-butyldimethylsilyl-10-hydroxycamptothecin inhibit cell proliferation by at least $75 \%$ in all tested cell lines of human malignant glioma.

PUF based on dextran [11] are known as a biomaterial for bone tissue engineering. According to the results of histological studies they are biocompatible. The studied PUF is an alternative to the known bone implants due to the good heat resistance in physiological conditions and the ability to restore the original shape after deformation.

Porous materials were obtained based on cross-linked polyurethane with immobilized biologically active substances (dacarbazine, albucid) as implant materials for use in soft tissue defects in ophthalmic and maxillofacial surgery [12]. It was found that the gradual ingrowth of tissue structures into the implants which prevented their rapid resorption occurred due to the porous structure of the polymer samples. The studied porous materials are biocompatible and biologically active. Implantation of polymer materials with dacarbazine led to the development of a long inflammatory process which can be a useful biological action in restorative and reconstructive operations after the removal of a malignant tumor.

The albucid - N-[(4-aminophenyl)sulfonyl] acetamide, or sulfacetamide deserves attention as a drug substance for creation of biologically active PUF for use in ophthalmic surgery. It is used in medical practice in the form of solution as eye drops $[13,14]$. The active substance of these drops is sodium sulfacetamide which is a sulfonamide antimicrobial drug with a broad spectrum of action. It also has a bacteriostatic effect. The mechanism of action is related with competitive antagonism with para-aminobenzoic acid and inhibition of dihydropteroate synthetase that leads to disruption of folic and nucleic acids synthesis, required for bacteria reproduction [13, 15]. Albucid is active against gram-positive and gram-negative bacteria such as streptococci, gonococci, pneumococci, Escherichia coli, Chlamydia spp., Actinomyces israelii and others [15]. Albucid is used in infectious-inflammatory eyes diseases caused by bacteria sensitive to the drug: conjunctivitis, blepharitis, corneal ulcer and others [13].

Thus, the use of albucid as a drug for immobilization in the polymer matrix, in particular polyurethane foam, opens the prospect of obtaining new biologically active polymeric implantation materials with antimicrobial action for use in ophthalmic surgery.

Therefore, the purpose of the work is to develop and investigate the properties of polyurethane foam composite materials with albucid as promising implants for use in ophthalmic surgery.

\section{Experimental}

\subsection{Materials}

Polyoxypropylene glycol (POPG) ("Rokopol", Poland) MM 2000 has been dried at residual pressure $1-3 \mathrm{~mm}$ of mercury and temperature $(80 \pm 5)^{\circ} \mathrm{C}$ in the flow of dry argon for 8 hours just prior to the synthesis.

2.4-; 2.6-toluylene diisocyanate (TDI, 80/20) $\mathrm{C}_{9} \mathrm{H}_{6} \mathrm{~N}_{2} \mathrm{O}_{2}$ (Merck, Germany) $\left(\mathrm{MM}=174.16 ; \quad \rho=1.22 \quad \mathrm{~g} / \mathrm{cm}^{3}\right.$; $\left.T_{\text {boil }}=(133 \pm 1)^{\circ} \mathrm{C} ; \mathrm{n}_{\mathrm{D}}{ }^{20}=1.5678\right)-$ mixture of isomers 2.4 - and 2.6- with the ratio of $80 / 20$, have been purified by distillation in vacuum at residual pressure $0.67 \mathrm{kPa}, \mathrm{T}_{\text {boil }}=(100 \pm 1)^{\circ} \mathrm{C}$. Freshly distilled has been used.

2,4,6-tris(dimethylaminomethyl)phenol

(UP-606/2) $\mathrm{C}_{15} \mathrm{H}_{27} \mathrm{~N}_{3} \mathrm{O}$ (Sigma-Aldrich, USA) (MM=265,39) has been used without any additional purification.

Albucid $\mathrm{C}_{8} \mathrm{H}_{10} \mathrm{~N}_{2} \mathrm{O}_{3} \mathrm{~S} \quad(\mathrm{MM}=214,243)$ has been used without any additional purification.

\subsection{Preparation of Polyurethane Foam and Polyurethane Foam Composite Materials with Albucid}

\subsubsection{Preparation of Polyurethane Foam}

Diisocyanate prepolymer (DPP) was synthesized based on POPG and TDI at a molar ratio of 1:3.7. $24.27 \mathrm{wt} . \%$ $(0.211 \mathrm{~mol})$ of TDI was placed in a three-necked reactor equipped with a mechanical stirrer, a separation funnel and an inert gas (argon) bubbler. 75.73 wt.\% (0.057 mol) of POPG was added dropwise from the separatory funnel with vigorous stirring for 1 hour at room temperature. Then the reactor was placed in an oil bath heated to $(60 \pm 5)^{\circ} \mathrm{C}$ and mixed continuously, sampling periodically to determine the content of free NCO groups (determined by titrometric method). The reaction was continued until the isocyanate content reached $7.3 \%$.

Polyurethane foams were prepared by mechanical mixing of DPP and catalyst UP-606/2 at a weight ratio of 1:0.006 on a Teflon substrate at room temperature for 1-2 minutes. The reaction mass was cured at room temperature for 24 hours.

\subsubsection{Preparation of Polyurethane Foam Composite Materials with Albucid}

DPP was synthesized based on POPG and TDI at a molar ratio of 1:3.7 similarly to the method described above. Polyurethane foam composite materials were obtained by sequential addition of albucid in an amount of $5 \mathrm{wt} \%$ and UP-606/2 to DPP stirring for 1-2 minutes. The composite material was cured at room temperature for 24 hours. 


\subsection{Study Methods}

\subsubsection{Fourier Transforms Infrared (ATR FTIR) Spectroscopy}

The structure was investigated on a Tensor-37 FTIR spectrometer in the range $650-4000 \mathrm{~cm}^{-1}$ by the MATR method with the aid of a diamond crystal trapezoidal prism (a number of reflections of $N=1$, an incidence angle of $\varphi=39^{\circ}$ ). The absorption bands were assigned as described in [16].

\subsubsection{Mechanical Tests}

The adhesive strength was determined on the tension testing machine P 5 in accordance with [ASTM D897-08 (2016) Standard Test Method for Tensile Properties of Adhesive Bonds]. The movement rate of the active clamp was $10 \mathrm{~mm} / \mathrm{min}$. Adhesive bonding were prepared using steel substrates.

The adhesive strength $(\sigma)$ was calculated using Equation (1) and (2):

$$
\begin{gathered}
\sigma=\frac{P}{F}, \\
F=\frac{\pi \cdot d^{2}}{4}
\end{gathered}
$$

Where: $P$ - breaking load, $\mathrm{H}$;

$F$ - gluing area, $\mathrm{m}^{2}$;

$d$ - diameter of sample, $\mathrm{m}$.

\subsubsection{Differential Scanning Calorimetry (DSC)}

Thermophysical properties (glass-transition temperature $\left(T_{\mathrm{g}}\right)$, changes of the heat capacity at the glass-transition temperature $\left.\left(\Delta C_{p}\right)\right)$ have been studied by the DSC method. The study has been carried out within the interval of temperature from -90 to $+200^{\circ} \mathrm{C}$ (TA Instrument Q2000) at a heating rate $20^{\circ} \mathrm{C} / \mathrm{min}$ under nitrogen atmosphere. Two heating procedures have been carried out to exclude the influence of the thermal and mechanical prehistory of the material.

\subsubsection{Thermal Gravimetric Analysis (TGA)}

Thermogravimetric characteristics (onset temperature of thermal decomposition $\left(\mathrm{T}_{0}\right)$, temperature of maximum decomposition rate $\left(T_{\max }\right)$, weight loss at $T_{0}$ ) were studied by TGA. The study has been carried out within the interval of temperature from +20 to $+700^{\circ} \mathrm{C}$ (TA Instrument Q50) at a heating rate $20^{\circ} \mathrm{C} / \mathrm{min}$ under an air atmosphere.

\subsubsection{Transmission Optical Microscopy (TOM)}

The morphology of the samples was studied on a Carl Zeiss Primo Star microscope at magnification of 1000 by TOM. The porous structure characteristics of the polymer foams were determined by photomicrograph analysis using the ImageJ program. Analysis of photomicrograph gave quantitative information about the range of pore sizes (diameters), pore size distribution and porosity percentage. The total porosity was calculated based on the area occupied by the pores.

\section{Results and Discussion}

\subsection{Preparation of Polyurethane Foam and Polyurethane Foam Composite Materials with Albucid}

Polyurethane foams were prepared by a prepolymer method in which the isocyanate first reacts with the polyol to form of urethane. Then the isocyanate reacts with air moisture to form an unstable carbamic acid, which immediately decomposes to amine and carbon dioxide. Foaming occurs due to the formation of carbon dioxide. The formed amine reacts with isocyanate to form urea. Isocyanate also reacts with urea and urethane to form biuret and allophanate, respectively, which leads to the cross-linking of the polymer.

Thus, the obtained PUF are a cross-linked polymer (Figure $1)$.



Figure 1. Structural formula of PUF.

To obtain biologically active PUF composite materials the albucid was added to the reaction mixture. Immobilization of albucid was investigated by IR spectroscopy.

\subsection{FTIR Spectroscopy}

To confirm the reaction of PUF formation, IR spectroscopic studies of the structure of DPP and PUF obtained on their basis were carried out. On the IR spectra of DPP the valence vibrations of the $\mathrm{C}=\mathrm{O}$ urethane group are represented by the absorption band with a maximum $1730 \mathrm{~cm}^{-1}$ (Figure 2, curve 1). On the spectra of the synthesized PUF this band is shifted towards lower frequencies region $\left(1718 \mathrm{~cm}^{-1}\right)$ that indicates the appearance of more bonded $\mathrm{C}=\mathrm{O}$-groups by hydrogen bonds. There is also the appearance of absorption band with a maximum $1653 \mathrm{~cm}^{-1}$ demonstrating the formation of urea groups (Figure 2, curve 2). The absorption band of $\mathrm{NCO}$ groups of DPP with a maximum $2272 \mathrm{~cm}^{-1}$ is absent on the PUF spectra that confirms the complete conversion of $\mathrm{NCO}$ groups as a result of the reaction.

The valence vibrations of $v_{\mathrm{NH}-\text { bonds }}$ of DPP are represented 
by an absorption band with a maximum $3295 \mathrm{~cm}^{-1}$ in the frequency range of the spectra 2800-3700 $\mathrm{cm}^{-1}$ (Figure 2, curve 1). The valence vibrations of the $v_{\mathrm{NH}-b o n d}$ of the synthesized PUF are manifested by a wide band with two approximate maximum 3281 and $3350 \mathrm{~cm}^{-1}$ (Figure 2, curve 2). In addition, on the spectra of PUF there is an increase in the intensity of the absorption bands of the valence vibrations of NH groups: $v_{\mathrm{NH} \text { bonds }}\left(3281\right.$ and $\left.3350 \mathrm{~cm}^{-1}\right)$ and $v_{\mathrm{NH} \text {-free }}$ with an approximate maximum of $3571 \mathrm{~cm}^{-1}$.

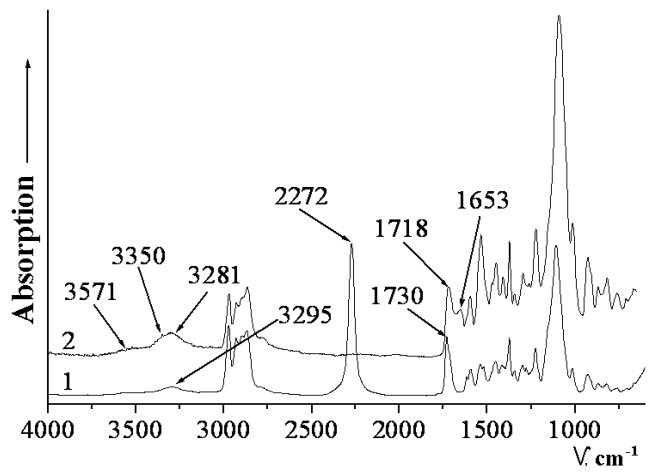

Figure 2. IR-spectra of DPP (1) and PUF (2).

To study the effect of albucid on the structure of the obtained materials, the IR spectra of PUF and PUF composite materials filled with the drug albucid on their basis were removed.

Comparing the IR spectra of PUF (Figure 3, curve 1) and PUF filled with albucid (Figure 3, curve 2) confirmed the absence of new absorption bands on the spectra of composite materials with albucid. It allows us to conclude that there is no chemical interaction of albucid with the polymer matrix.

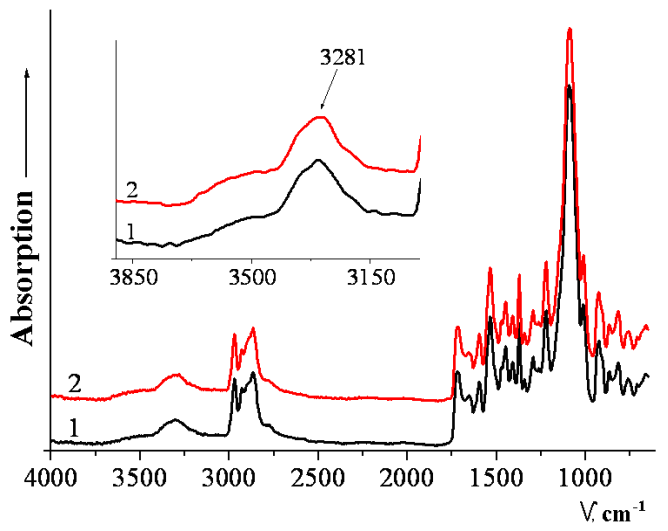

Figure 3. IR-spectra of PUF (1) and PUF composite material with albucid (2)

On the spectra of PUF with albucid there is a slight expansion of the maximum $3281 \mathrm{~cm}^{-1}$ of absorption band $v_{\mathrm{NH}-b o n d}$. Such changes indicate about the presence of hydrogen bonds of NH-groups that differ in bond strength. Therefore, it can be concluded that albucid is immobilized physically by intermolecular hydrogen bonds.

\subsection{Mechanical Tests}

According to the results of physical-mechanical tests, the value of adhesive strength does not depend on the presence of albucid in the composition of PUF (Table 1).

Table 1. Adhesion strength of PUF and PUF composite material with albucid.

\begin{tabular}{lll}
\hline Samples & Albucid content, wt.\% & $\boldsymbol{\sigma}, \mathbf{M P a}$ \\
\hline PUF & - & 1.16 \\
PUF+albucid & 5 & 1.16 \\
\hline
\end{tabular}

It is known that the adhesive strength of PUF composite materials filled by lysozyme in amount of 1, 3 and 5 wt.\% depend on the presence of lysozyme in their composition. The introduction of lysozyme into the PUF and increase its content leads to a decrease of adhesive strength. The authors associate this with a decrease in the packing density of macrochains of PUF matrix [17].

In our study, the presence of albucid does not affect the adhesive strength. This is probably due to the low molecular weight of albucid (it is 214,243). Whereas the molecular weight of lysozyme is 14000 . Therefore, albucid molecules are distributed in the PUF matrix without changing the packing density of macrochains.

\subsection{Thermal Gravimetric Analysis}

Since the synthesized materials are medical polymer materials the use of which requires thermal sterilization before use, there is a need to study their thermophysical properties.

According to TGA, onset temperature of thermal decomposition $\left(\mathrm{T}_{\mathrm{o}}\right)$ of synthesized PUF is $172.05^{\circ} \mathrm{C}$, while $\mathrm{T}_{\mathrm{o}}$ of PUF with albumide is $162.84^{\circ} \mathrm{C}$ and accompanied by a slight weight loss $(0.78$ and $0.87 \%$ respectively) (Table 2$)$.

Table 2. Thermogravimetric characteristics of PUF and PUF composite material with albucid.

\begin{tabular}{llll}
\hline Samples & $\mathbf{T}_{\mathbf{0}},{ }^{\circ} \mathbf{C}$ & $\mathbf{T}_{\max }{ }^{\circ} \mathbf{C}$ & Weight loss at $\mathbf{T}_{\mathbf{0}} \mathbf{\%}$ \\
\hline PUF & 172.05 & 313.26 & 0.78 \\
PUF+albucid & 162.84 & 303.83 & 0.87 \\
\hline
\end{tabular}

The decomposition of samples occurs in one step with a maximum decomposition rate of $313.26^{\circ} \mathrm{C}$ (for PUF) and $303.83^{\circ} \mathrm{C}$ (for PUF with albumide).

Thus, the introduction of albucid into the PUF causes a decrease in $\mathrm{T}_{\mathrm{o}}$ with simultaneous increase of weight loss and a decrease of $T_{\max }$.

\subsection{Differential Scanning Calorimetry}

According to DSC, the temperature dependences of the heating capacity of PUF and PUF with albucid appeared to be quite similar (Figure 4). One glass transition and, accordingly, one glass-transition temperature $\left(\mathrm{T}_{\mathrm{g}}\right)$ have been found on the thermograms of the studied PUF. Therefore, the studied samples are single-phase systems.

$\mathrm{T}_{\mathrm{g}}$ of the 2 nd heating procedure of the studied materials is in the range from -48.40 to $-48.64^{\circ} \mathrm{C}$ (Table 3) and does not depend on the albucid content in their composition.

The introduction of albucid into the PUF causes a decrease of $\Delta \mathrm{C}_{\mathrm{p}}$ during the first and second heating procedure (Table 3). This is due to the fact that the segmental mobility of 
macromolecules decreases as a result of the transition of some of the macromolecules into boundary layers.

Table 3. Thermophysical properties of PUF and PUF composite material with albucid.

\begin{tabular}{|c|c|c|c|c|}
\hline \multirow{2}{*}{ Samples } & \multicolumn{2}{|l|}{$T_{\mathrm{g}},{ }^{\circ} \mathrm{C}$} & \multicolumn{2}{|l|}{$\Delta C_{\mathrm{p}}, \mathbf{J} /\left(\mathrm{g} \cdot{ }^{\circ} \mathbf{C}\right)$} \\
\hline & 1st heating procedure & 2nd heating procedure & 1st heating procedure & 2nd heating procedure \\
\hline PUF & -47.42 & -48.64 & 0.2667 & 0.2767 \\
\hline PUF+albucid & -46.95 & -48.40 & 0.2092 & 0.2429 \\
\hline
\end{tabular}

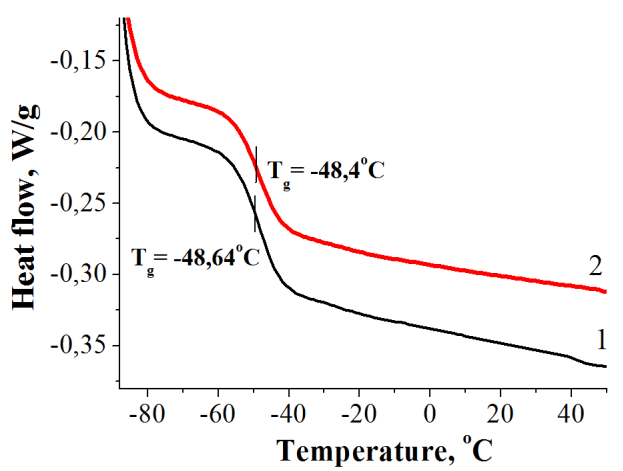

Figure 4. The typical thermograms of PUF (1) and PUF composite material with albucid (2) (2nd heating procedure).

So, according to the research results, synthesized PUF composite materials with albucid are heat-resistant materials to a temperature of $162.84^{\circ} \mathrm{C}$, which makes it possible to carry out dry sterilization of samples without changing their characteristics.

\subsection{Transmission Optical Microscopy}

According to TOM, the investigated PUF composite materials have a microporous structure that depends on the filler content in their composition. Most pores are ovalshaped pores (Figure 5).


Figure 5. TOM photomicrograph of PUF (a) and PUF composite material with albucid (b).

Pores with a diameter of 69.9-1519.0 $\mu \mathrm{m}$ were found for PUF (Table 4). By considering the histograms of the pore size distribution, it became obvious that a larger quantity of pores $(69.5 \%)$ has a diameter less than $300 \mu \mathrm{m}$. Single large pores with a diameter of $997.1 \mu \mathrm{m}, 1054.7 \mu \mathrm{m}$ and 1519.0 $\mu \mathrm{m}$ were detected (Figure 6).

Table 4. Porosity characteristics of PUF and PUF composite material with albucid.

\begin{tabular}{lll}
\hline Samples & Pore diameter, mkm & Porosity, \% \\
\hline PUF & $69.9-1519.0$ & 61.5 \\
PUF+albucid & $43.2-953.8$ & 51.1 \\
\hline
\end{tabular}
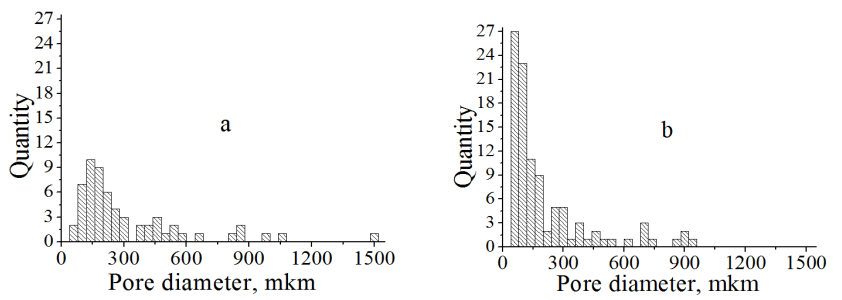

Figure 6. Histograms of pore-size distribution of PUF (a) and PUF composite material with albucid (6).

Pores with a diameter of 43.2-953.8 $\mu \mathrm{m}$ were found for PUF composites with albucid (Table 4). A larger quantity of pores $(82 \%)$ has a diameter less than $300 \mu \mathrm{m}$ (Figure 6).

The porosity of PUF is $61.5 \%$, while the porosity of PUF composite materials with albucid is $51.1 \%$ (Table 4 ). That is the introduction of albucid into the PUF causes a decrease in porosity.

So, the analysis of TOM photomicrograph allowed estimating the pore diameter, pore size distribution and porosity percentage. It also made it possible to establish that the porosity characteristics depend on the albucid content in the composition of PUF. By considering the histograms of the pore size distribution, it became obvious that the presence of albucid in the composite materials leads to a decrease in porosity, an increase in the quantity of pores with a diameter less than $300 \mu \mathrm{m}$, which is $82 \%$ (while for PUF it is $69.5 \%$ ) and also a decrease in both the minimum and maximum pore size (there is no pore with a diameter more than $954 \mu \mathrm{m}$ ). Therefore, it can be concluded that the introduction of albucid into the PUF causes an increase in the quantity of smaller pore diameters and a decrease in the porosity percentage.

The result is a positive effect, because, firstly, the contact area of the composite with the wound surface increases and, secondly, the presence of a larger number of small pores reduces the likelihood of acute inflammatory process by reducing exudation around the polymer material.

Therefore, the obtained PUF composites with albucid have a porous structure and it have a developed surface that is capable of stimulating tissue regeneration processes at the implantation site $[5,6]$.

Considering the obtained results, PUF composite materials with albucid can be proposed for follow-up biomedical research.

\section{Conclusions}

Polyurethane foam composite materials with albucid in the amount of 5 wt.\% based on diisocyanate prepolymer were obtained. It is established that the immobilization of albucid 
occurs due to intermolecular hydrogen bonds by the method of IR spectroscopy. The influence of albucid on the physicalmechanical and thermophysical properties of the obtained materials was studied. It was shown that the presence of albucid in the PUF composition does not affect the value of adhesive strength and $T_{g}$ of composite materials. The introduction of albucid into the PUF leads to a decrease of $\Delta \mathrm{C}_{\mathrm{P}}$, which is due to a decrease in segmental mobility of macromolecules. According to DSC the investigated systems are single-phase. Obtained PUF with albucid is heat-resistant materials to a temperature of $162.84^{\circ} \mathrm{C}$, which makes it possible to carry out dry sterilization of samples without changing their characteristics. The obtained PPU composites are characterized by a microporous structure that depends on the filler content in their composition. It was found that the presence of albucid in the composites leads to a decrease in the porosity and an increase in the quantity of smaller pore diameters. Thus, the obtained PUF with albucid are promising materials that can be used in medical practice as implants in ophthalmic surgery and require further biomedical tests.

\section{References}

[1] Smirnov, S. V. Shakhlamov M. V., Litinsky M. A., Yanshin D. V., Sachkov A. V., Obolensky V. N. Polyurethane foam covering for wounds, burns and ulcers. Wound Medicine, 2013, № 2-3, 6-8. https://doi.org/10.1016/j.wndm.2013.10.001.

[2] Namviriyachote N., Lipipun V., Akkhawattanangkul Y., Charoonrut P., Ritthidej G. C. Development of polyurethane foam dressing containing silver and asiaticoside for healing of dermal wound. Asian Journal of Pharmaceutical Sciences, 2019, 14 (1): 63-77. https://doi.org/10.1016/j.ajps.2018.09.001.

[3] Lee S. M., Park I. K., Kim Y. S., Kim H. J., Moon H., Mueller S., Jeong Y.-I. Physical, morphological, and wound healing properties of a polyurethane foam-film dressing. Biomaterials Research, 2016, 20, 15. https://doi.org/10.1186/s40824-0160063-5.

[4] Karpenko O. S., Galatenko N. A., Kiseleva T. A., Narozhayko L. F. Synthesis of new polyurethane foams for medical use. Polymer journal, 2018, 40 (1): 51-57.

[5] Galatenko N., Rozhnova R. Biologically active polymer materials for medicine. Kyiv: Naukova dumka, 2013. 210 p.

[6] Buckley M. J., Beckman E. J. Adhesive Use in Oral and Maxillofacial Surgery. Oral and maxillofacial surgery clinics of North America, 2010, 22 (1): 195-199. https://doi.org/10.1016/j.coms.2009.10.008.

[7] Bufius N., Galatenko N. Patent US 5474779A, Compositions for aiding in the regeneration of tissue with a prolonged immunomodulating effect. publ. 12.12.1995.
[8] K. Lei, Q. Zhu, X. Wang, H Xiao, Z. Zheng. In Vitro and in Vivo Characterization of a Foam-Like Polyurethane Bone Adhesive for Promoting Bone Tissue Growth. ACS Biomaterials Science \& Engineering, 2019, 5 (10): 54895497. http://dx.doi.org/10.1021/acsbiomaterials.9b00918.

[9] Lebedev Ye. V., Galatenko N. A., Rozhnova R. A., Kulesh D. V. Serial Production of Domestic Biologically Active Glue for Medical Purposes. Science and innovation, 2016, 12 (1): 6165. http://dx.doi.org/10.15407/scine12.01.054.

[10] Sivak W. N., Pollack I. F., Petoud S., Zamboni W. C., Zhang J., Beckman E. J. Catalyst-dependent drug loading of LDIglycerol polyurethane foams leads to differing controlled release profiles. Acta Biomaterialia, 2008, 4, 1263-1274. https://doi.org/10.1016/j.actbio.2008.01.008.

[11] Gerges I., Tamplenizza M., Lopa S., Recordati C., Martello F., Tocchio A., Ricotti L., Arrigoni C., Milani P., Moretti M., Lenardi C. Creep-Resistant Dextran-Based Polyurethane Foam as a Candidate Scaffold for Bone Tissue Engineering: Synthesis, Chemico-Physical Characterization, In vitro and In vivo Biocompatibility. International Journal of Polymeric Materials and Polymeric Biomaterials, 2016, 65 (14): 729740. https://doi.org/10.1080/00914037.2016.1163565.

[12] Galatenko N. A., Kulyesh D. V., Maletskyi A. P., Karpenko O. S. Soft-tissue response to synthetic polymer implants made of cross-linked polyurethane and containing a biologically active substance, albucid or dacarbazine, in animals. Journal of Ophthalmology, 2018, № $6, \quad 52-58$. http://doi.org/10.31288/oftalmolzh201865258.

[13] Abdullah N., Karamat F., Qamar S., Abbas M., Khan A. M., Ullah N. Development and validation of RP-HPLC method for simultaneous quantification of sulfacetamide sodium and prednisolone sodium phosphate. Acta Poloniae Pharmaceutica n Drug Research, 2019, $76 \quad$ (1): 37-47. http://doi.org/10.32383/appdr/93843.

[14] Sheshala R., Ming N. J., Kok Y. Y., Raj Singh T. R., Dua K. Formulation and Characterization of $\mathrm{pH}$ Induced in situ Gels Containing Sulfacetamide Sodium for Ocular Drug Delivery: A Combination of Carbopol $\mathbb{R} /$ HPMC Polymer. Indian Journal of Pharmaceutical Education and Research, 2019, 53 (4): 654-662. http://doi.org/10.5530/ijper.53.4.127.

[15] Guliy O. I., Bunin V. D., Balko A. B., Volkov A. A., Staroverov S. A., Karavaeva O. A., Ignatov O. V. Effect of Sulfonamides on the Electrophysical Properties of Bacterial Cells. Anti-Infective Agents, 2014, 12 (2): 191-197. http://doi.org/10.2174/2211352512666140630171501.

[16] Pretsch E., Bëllmann P., Affolter C. Structure determination of organic compounds. Tables of Spectral Data. Springer-Verlag Berlin Heidelberg, 2009. 433 p.

[17] Vislohuzova T. V., Rozhnova R. A., Galatenko N. A. Development and research of polyurethane foam composite materials with lysozyme. Polymer journal, 2021, 43 (3). 